\title{
Characteristics of New Permanent Magnetic Eddy Current Drive System of the Scraper Conveyor
}

shuang wang ( $\nabla$ shuangw094@126.com )

Anhui University of Science and Technology https://orcid.org/0000-0002-6452-778X

Yongcun GUO

Anhui University of Science and Technology

Deyong LI

Anhui University of Science and Technology

Research

Keywords: Eddy Current Drive, Scraper Conveyor, Acceleration of the scraper chain, Permanent magnet

Posted Date: May 25th, 2021

DOI: https://doi.org/10.21203/rs.3.rs-548513/v1

License: (1) This work is licensed under a Creative Commons Attribution 4.0 International License.

Read Full License 


\title{
Characteristics of New Permanent Magnetic Eddy Current Drive System of the Scraper Conveyor
}

\author{
Shuang WANG ${ }^{1,2}$,Yongcun $\mathrm{GUO}^{1,2^{*}}$, Deyong $\mathrm{LI}^{2}$ \\ ${ }^{1}$ State Key Laboratory of Mining Response and Disaster Prevention and Control in Deep Coal Mines, Anhui \\ University of Science and Technology, Huainan, Anhui 232001, China; \\ ${ }^{2}$ College of Mechanical Engineering, Anhui University of Technology, Huainan, Anhui 232001, China; \\ (C) The Editorial Office of Journal of Coal Science and Technology and Springer-Verlag Berlin Heidelberg 2014
}

\begin{abstract}
This study provides a new permanent magnetic eddy current drive system to solve the ener-gysaving drive problem of the scraper conveyor working under bad conditions, including overload startup, severe abrasion and pollution. Considering the practical conveying conditions of the scraper chain on a fully mechanised coal mining face, this study creates a mathematical model for the new permanent magnetic eddy current drive system of the scraper conveyor based on its characteristics and indicates the motion characteristics of the scraper chain driven by two wheels. This study verifies the model accuracy with a prestartup technology depending on the scraper conveyor on the No. 12318 working face of the 8th coal mine in the West No. 1 mining area of the Pansan Coal Mine of the Huainan Mining Group. According to the results, the motion acceleration of the scraper chain based on the new permanent magnetic eddy current drive is lower than that of the scraper chain with a hydraulic coupler under the same running condition and load during startup and acceleration and declines by approximately $14.7 \%$. Consequently, this can decline the startup impact due to the serious abrasion and frequent overload of the scraper chain working under bad conditions.
\end{abstract}

Keywords Eddy Current Drive; Scraper Conveyor; Acceleration of the scraper chain; Permanent magnet

\section{Introduction}

The scraper conveyor reliability can directly influence the safe and highly efficient production of modern coal mines as a key equipment for coal mining on a fully mecha-nised coal mining face(M. V. Kurlenya 2019). Statistics show that fault is most likely to occur in the scraper chain of which the ratio of the faults, including chain disconnection, jumping and drop-ping, is $40 \%$ out of the total number of scraper conveyor faults(Pan X. et al 2020; Pan Q. et al 2019). Many defects of the current drive system, such as polluted medium, low transmission efficiency, high instal-lation accuracy, large occupied area, high maintenance fee and short service life(Jiang S. et al 2020), par-ticularly result in the high ratio of faults and long maintenance time for the scraper chain, which seriously restrict the production efficiency of the large-scale coal mines in China(Ball A. S. and Kessel J. C. V. 2019.).

Therefore, many domestic and foreign scholars performed many studies on the drive characteristics of the scraper conveyor. Cenacewicz Krzysztof and
Katunin Andrzej used the simulator eight scenarios to generate typical of usual operational conditions of an un-derground scraper conveyor and presented the analysis of various combinations of sce-narios of operation and faults with description(Cenacewicz K. and Katunin A .2017).Ordin, A. A and Metel'kov, A. A. (2015) analysed the basic mechanisms in variation of output of longwall face versus its length in the cutterloader and scrape conveyor system in underground mining of flat-lying coal beds and determined the dependence between the maximum output of longwall face and the longwall length. Xie Chunxue et al. (2018) theoretically analysed the dynamic characteristics of the chain drive system and conducted a simulated analysis and an experimental study on these dynamic characteristics, including speed and tension, under the fault condi-tion. Lu En et al.(2020) analysed the contact features of the chain wheel and created a dynam-ic model for the dual-motor driven scraper conveyor. Xie Jia-cheng et al.(2018) studied the dynamic action and the contact response of the chain drive system under a loaded startup. Zhang Dongsheng et al.(2016) studied 
the prominent time-varying and nonlinear coupling feature of the scraper conveyor during the startup and braking stages by a simu-lated analysis and experimental testing. Haijian Wang, et al. (2017) designed a dynamic ten-sion test and an intelligent coordinated control system for the monitoring of the dynamic tension of a heavy scraper conveyor and the realisation of coordinated control for driving scraper conveyor sprockets under a heavy load. Zhiyuan Shi and Zhencai Zhu (2020) per-formed multiple sets of wear tests in order to simulate the range in working conditions of the super heavy-load scraper conveyor and the results indicate that the wear loss of the middle plate increases with the contact pressure and sliding speed with the same compo-sition mixed material. Shangqing HAO, et al.(2017) constructed a track geometry surveying model of the scraper conveyor based on the position of the shearer, to maintain the straightness of an unmanned longwall mining face(W. GUO, et al. 2017). The surveying instrument was developed employing an inertial measurement unit and axial encoder.

In order to solve these problems, a new complex magnetic coupler is proposed in this paper. The traditional drum magnetic coupler and the double-disc magnetic coupler are optimized and combined to increase the area of the induced magnetic field and simultaneously magnetize from the axis/radial direction to improve the transfer efficiency, in or-der to reduce the impact vibration of the scraper conveyor starting.

\section{Mathematical model for the new permanent magnetic eddy current drive system of the scraper conveyor}

The new drive system based on the permanent magnetic eddy current technology consists of a motor, a combined magnetic coupler, a reduction unit and a scraper conveyor. When the drive system is running, the revolving speed $\mathrm{n} 1$ and the torque $\mathrm{T} 1$ of the motor are transmitted to the input end (i.e. copper conductor disc) of the combined magnetic coupler. According to the law of electromagnetic induction, the output revolving speed $\mathrm{n} 2$ and the torque $\mathrm{T} 2$ at the output end (i.e. permanent magnetic disc) of the combined magnetic coupler are transmitted to the reduction unit to increase the torque and decrease the revolving speed based on the reduction ratio $i$. The output revolving speed $n 3$ and the torque $\mathrm{T} 3$ of the reduction unit are then transmitted to the chain wheel (Figure 1).

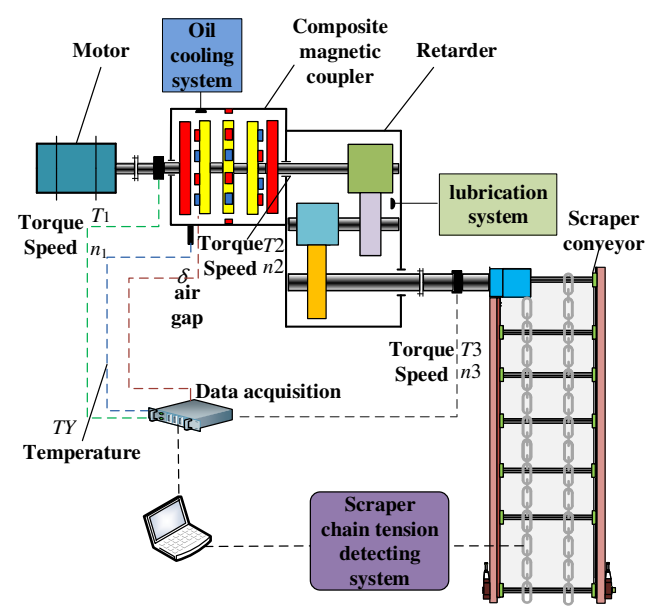

Fig. 1 Schematic diagram of new permanent magnet eddy current drive system for scraper conveyor

\subsection{Drive characteristics of the combined magnetic coupler}

By combining a conventional cylinder magnetic coupler with a dual-disc magnetic coupler, this study introduces a new magnetic coupler or a combined magnetic coupler that can increase the area of the induced magnetic field and improve the transmission efficiency by magnetisation at the axial and radial directions. Realize in the same volume or size of the case, greatly improve the transmission power, and in the case of a certain transmission power, can reduce the volume and size of the coupler, reduce the space occupied, Fig. 2 is its structure diagram.

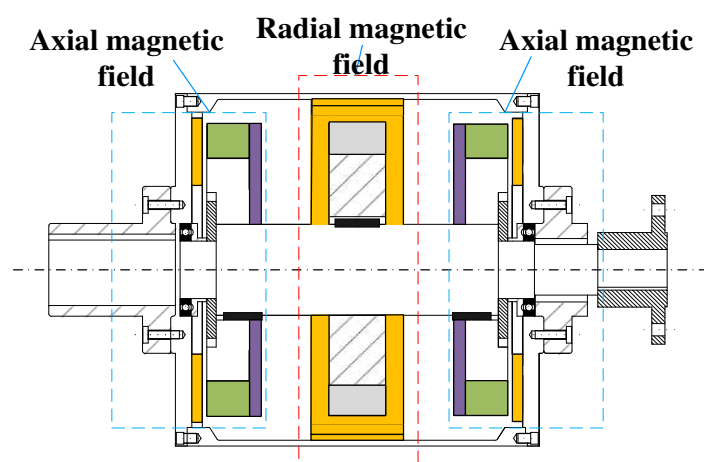

Fig.2 Schematic diagram of axial and radial magnetic fields If $r_{1}$ and $r_{2}$ are the inner and outer diameters of the copper disc at the axial direction (unit: $\mathrm{mm}$ ), $r_{3}$ and $r_{4}$ are the inner and outer diameters of the copper ring at the radial direction (unit: $\mathrm{mm}$ ). The copper disc at the axial direction includes infinite copper with a length $\left(r_{2}-r_{1}\right)$ across the centre of a circle. The copper ring at the radial direction includes infinite copper with a length $\left(r_{4}-r_{3}\right)$ across the centre of a circle (Figure 3). 


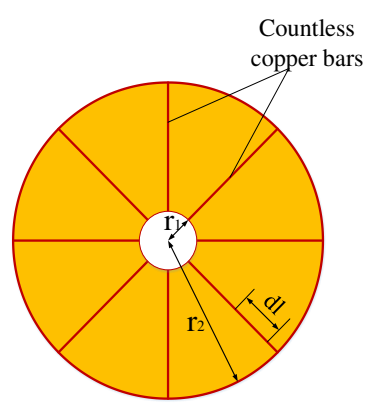

(a) Axial copper disk

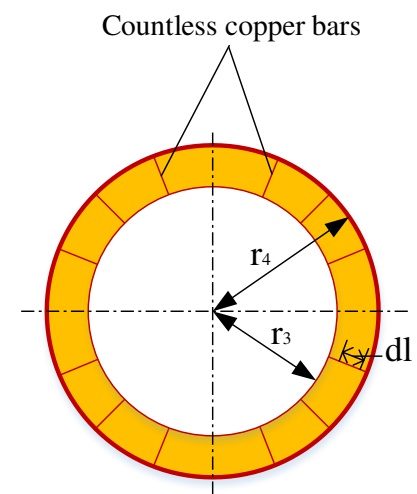

(b) Radial copper ring

Fig. 3 Equivalent structure diagram

The induced electromotive force from the section $\mathrm{dl}$ of the copper bar is

$$
\mathrm{d} \varepsilon=B_{\mathrm{g}} \omega_{\mathrm{s}} \cdot \sin \left(\omega_{\mathrm{s}} t\right) \mathrm{d} l
$$

where, $B_{\mathrm{g}}$ is the flux density in gap (unit: T); $\omega_{\mathrm{s}}$ is the slip angular speed of the copper disc at the axial direction or copper ring at the radial direction relative to the permanent magnetic disc; and $\omega_{\mathrm{s}}=\omega_{1}-\omega_{2}$, where $\omega_{1}$ and $\omega_{2}$ are the angular speeds of rotation of the copper conductor (or copper ring) and the permanent magnetic disc at the axial or radial direction, respectively.

If $s$ is the slip ratio, and the calculation formula of the slip ratio is as follows,

$$
s=\frac{\omega_{1}-\omega_{2}}{\omega_{1}}
$$

then after variation,

$$
\omega_{\mathrm{s}}=2 \pi n_{1} s / 60
$$

where, $n_{1}$ is the revolving speed of the motor (i.e. input revolving speed) (unit: $r / \mathrm{min}$ ).

The slip power is mainly lost in the thermal form on the copper conductor, flange, yoke and permanent magnet. However, compared to the thermal loss on the copper conductor, the thermal loss of the rest three objects can be neglected. Therefore, the slip loss is usually considered to be equivalent to the eddy current loss of the copper conductor during the project design. The torque transmitted from the per-pole permanent magnet can be obtained as follows:

$$
\left\{\begin{array}{l}
T_{2}^{\prime}=T_{2 \mathrm{a}}+T_{2 \mathrm{r}} \\
T_{2 \mathrm{a}}=\frac{P_{\mathrm{sa}}}{\omega_{\mathrm{s}}} \\
T_{2 \mathrm{r}}=\frac{P_{\mathrm{sr}}}{\omega_{\mathrm{s}}}
\end{array}\right.
$$

where, $T_{2 \mathrm{a}}$ is the torque transmitted from the per-pole permanent magnet at the axial direction (unit: $\mathrm{N} / \mathrm{m}$ ); $T_{2 \mathrm{r}}$ is the torque transmitted from the per-pole permanent magnet at the radial direction (unit: $\mathrm{N} / \mathrm{m}$ ); and $T_{2}{ }^{\prime}$ is the sum of the torque transmitted from the per-pole permanent magnet (unit: $\mathrm{N} / \mathrm{m})$.

The transmission efficiency $\eta_{1}$ of the combined magnetic coupler is presented as follows:

$$
\eta_{1}=1-\frac{p_{\mathrm{s}}}{p_{\text {in }}}=1-\frac{\omega_{\mathrm{s}}}{\omega_{\text {in }}}
$$

where, $p_{\mathrm{s}}$ is the total eddy current loss, $p_{\text {in }}$ is the input power of magnetic coupler, $\omega_{\text {in }}$ is the input angular velocity of magnetic coupler.

According to the above formula, the transmission efficiency of the combined magnetic coupler is related to the speed difference between the active and driven rotors. The smaller the speed difference, the higher the transmission efficiency.

The following can then be obtained:

$$
\left\{\begin{array}{c}
T_{2 \mathrm{a}}=\frac{\omega_{\mathrm{s}} \pi \sigma \Delta \sin \left(\omega_{\mathrm{s}} t\right)\left(r_{2}^{2}-r_{1}^{2}\right)^{2}}{4 k_{\mathrm{R}} N_{\mathrm{P}} \sqrt{\ln \left(\frac{r_{2}}{r_{1}}\right)}} B_{\mathrm{g}}{ }^{2} \\
T_{2 \mathrm{r}}=\frac{\omega_{\mathrm{s}} \pi \sigma \Delta \sin \left(\omega_{\mathrm{s}} t\right)\left(r_{4}^{2}-r_{3}^{2}\right)^{2}}{4 k_{\mathrm{R}} N_{\mathrm{P}} \sqrt{\ln \left(\frac{r_{4}}{r_{3}}\right)}} B_{\mathrm{g}}{ }^{2}
\end{array}\right.
$$

where, $\Delta$ is the skin depth of the copper conductor (unit: $\mathrm{mm})$ and $k_{\mathrm{R}}$ is the correction factor of the resistance under different revolving speeds. According to the verification (D. YAN, et al.2003), $k_{\mathrm{R}}$ varies between 0.6 and 4.6.

According to Formula (6), the transmission torque of the combined magnetic coupler is related to the gap length and the slip speed at the axial and radial directions. The smaller the gap, the larger the air gap permeance. Consequently, the torque increases. However, when the gap is certain, a maximum value can be obtained among the transmitted torques. The transmitted torque increases and decreases with the slip speed increase.

Therefore, the total torque $T_{2}$ delivered from the combined magnetic coupler is calculated as (S. WANG, et al.2019)

$$
T_{2}=2 N_{\mathrm{pr}} \cdot T_{2 \mathrm{r}}+2 N_{\mathrm{pa}} \cdot T_{2 \mathrm{a}}
$$

where, $N_{\mathrm{pa}}$ is the number of pole pairs at the axial direction, and $N_{\mathrm{pr}}$ is the number of pole pairs at the radial direction.

\subsection{Working characteristics of the reduction unit}

A large revolving speed and an insufficient torque may be acquired if the input revolving speed and the output torque of the combined magnetic coupler are directly transmitted to the chain wheel of the scraper conveyor. Therefore, the revolving speed must be reduced, and the torque must be improved with the reduction unit:

$$
\begin{aligned}
& T_{3}=\eta_{2} T_{2} \omega_{2} / \omega_{3} \\
& i=\frac{\omega_{2}}{\omega_{3}}
\end{aligned}
$$

where, $\eta_{2}$ is the transmission efficiency of the reduction unit; $i$ is the reduction ratio; and $\omega_{3}$ is the angular velocity of the output shaft on the reduction unit (unit: $\mathrm{r} / \mathrm{min}$ ). Therefore, 
the working characteristics of the reduction unit can be expressed as follows:

$$
T_{3}=\eta_{2} i T_{2}
$$

\subsection{Motion characteristics of the dual-wheel-driven scraper chain}

The chain speed of the scraper conveyor is mainly related to the component at the meshing point along the running direction. When the scraper conveyor is running, the tightening-side chain continuously applies tension to the engaging-in ring, which maintains a one-side engaging side together with the gear teeth on the chain wheel. The stress applied to the chain wheel can be analysed with the dual-side contact model (Figure 4).

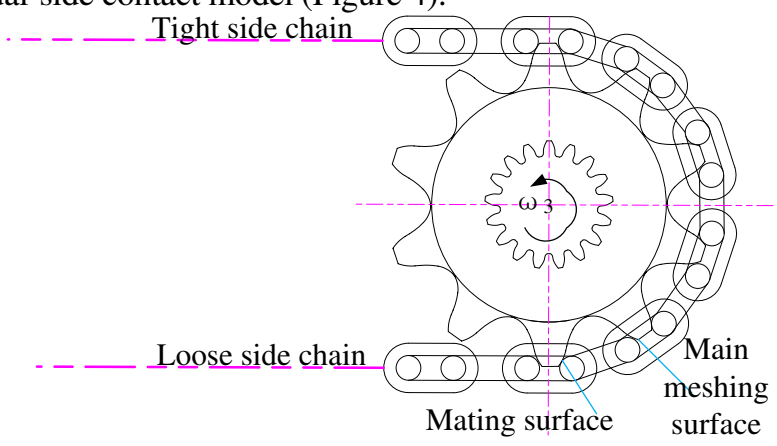

Fig.4 Stress diagram of sprocket
Let the inclined angles between the adjacent contact points be $\alpha$ and $\beta$ in the dual-side contact model. We then obtain

$$
\left\{\begin{array}{l}
\alpha=2 \arcsin (p+d / 2 R) \\
\beta=2 \arcsin (p-d / 2 R)
\end{array}\right.
$$

Then the fluctuation speed of scraper chain is

$$
v=\left\{\begin{array}{l}
D \omega_{3} \cos \theta_{1} / 2, \theta_{1} \in[-\alpha / 2, \beta / 2] \\
D \omega_{3} \sin \theta_{2} / 2, \theta_{2} \in[-\beta / 2, \alpha / 2]
\end{array}\right.
$$

Then the fluctuation acceleration of scraper chain is

$$
a=\left\{\begin{array}{l}
-D \omega_{3}^{2} \sin \theta_{1} / 2, \theta_{1} \in[-\alpha / 2, \beta / 2] \\
-D \omega_{3}^{2} \cos \theta_{2} / 2, \theta_{2} \in[-\beta / 2, \alpha / 2]
\end{array}\right.
$$

where, $R$ is the pitch radius of the chain wheel (unit: $\mathrm{m}$ ); $\omega_{3}$ is the angular speed of the drive chain wheel (unit $\mathrm{rad} / \mathrm{s}$ ); $v$ is the movement speed of the scraper chain (unit: $\mathrm{m} / \mathrm{s}$ ); $v_{\max }$ is the maximum movement speed of the scraper chain (unit: $\mathrm{m} / \mathrm{s}) ; v_{\min }$ is the minimum motion speed of the scraper chain (unit: $\mathrm{m} / \mathrm{s}$ ); $v_{\mathrm{m}}$ is the average motion speed of the scraper chain unit: $\mathrm{m} / \mathrm{s}$ ); $\theta_{1}$ and $\theta_{2}$ are the inclined angles between the components with the real and average speeds at the engaging point of the chain wheel (unit: ${ }^{\circ}$ ); $D$ is the pitch diameter of the chain wheel (unit: $\mathrm{mm}$ ); $p$ is the scraper chain pitch; and $d$ is the scraper chain diameter (unit: $\mathrm{mm}$ ).

According to the analysis, the maximum acceleration of The real motion speed of the scraper chain is not only the scraper chain increases with its pitch and diameter, while related to the running speed at the contact point between the non-uniform coefficient of the chain speed varies with the engaging-in ring and the main engaging surface of the the pitch diameter of the chain wheel, pitch and diameter of chain wheel but also related to the motion curve at the the scraper chain.

contact point between the secondary engaging surfaces. Figure 5 shows the dual-side contact model.

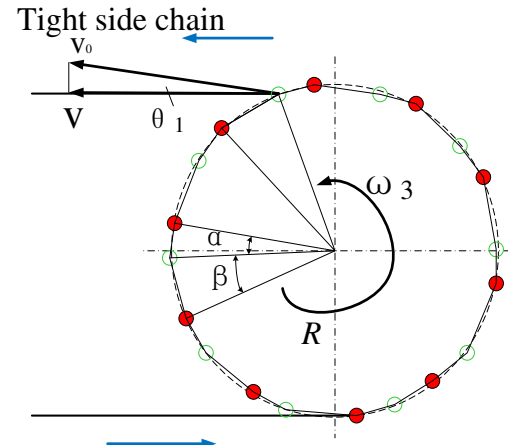

Loose side chain

(a)

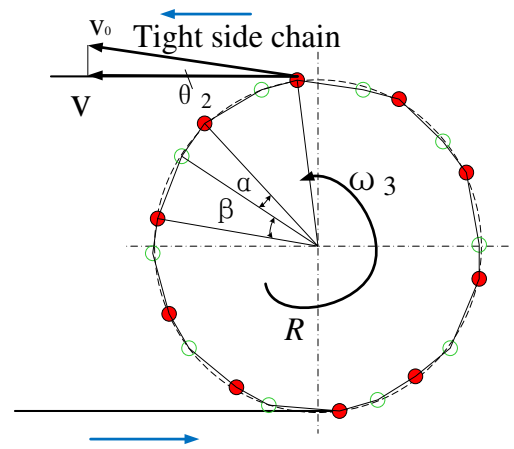

Loose side chain

(b)

Fig.5 Bilateral contact model;(a) Left-hand contact model; (b) Right-hand contact model

The motion speed and the acceleration of the scraper chain during the running process can be calculated with the dual-side contact model shown in Figure 5.

\subsection{Characteristics of the new permanent magnetic eddy current drive system}

A mathematical model for the new drive system is created with formulae (7), (15) and (11)-(13) based on the working features of the combined magnetic coupler, reduction unit and scraper conveyor:

$$
\begin{aligned}
& T_{3}=2 \eta_{2} i B_{g}{ }^{2}\left(i \omega_{3}-\omega_{1}\right) \pi \sigma \Delta \sin \left[\left(i \omega_{3}-\omega_{1}\right) t\right] . \\
& {\left[\frac{N_{p r}\left(r_{4}^{2}-r_{3}^{2}\right)}{4 k_{R} N_{P} \sqrt{\ln \left(r_{4} / r_{3}\right)}}+\frac{N_{p a}\left(r_{2}^{2}-r_{1}^{2}\right)}{4 k_{R} N_{P} \sqrt{\ln \left(r_{2} / r_{1}\right)}}\right]} \\
& \omega_{3}=\left\{\begin{array}{l}
-\sqrt{\frac{2 a}{D \sin \theta_{1}}}, \theta_{1} \in[-\alpha / 2, \beta / 2] \\
-\sqrt{\frac{2 a}{D \cos \theta_{2}}}, \theta_{2} \in[-\beta / 2, \alpha / 2]
\end{array}\right.
\end{aligned}
$$

where, $a$ is the motion acceleration of the scraper chain (unit: $\mathrm{m} / \mathrm{s}^{2}$ ).

\section{Results and discussion}

The experimental testing was conducted with same-size parameters to further verify the characteristics of the new permanent magnetic eddy current drive system. Fig. 6 shows the testing equipment for the scraper conveyor working on the No. 12318 working face of the 8th coal mine in the West No. 1 mining area of the Pansan Coal Mine of the Huainan Mining Group. The 'three-machine' equipment consists of a ZZ6400/18/38 hydraulic rack, an MG400/940-QWD coal mining machine and an SGZ-800/1050 scraper conveyor. The motion acceleration and the strain of the scraper chain under the no-load condition were tested with the BFH1201AA-Y3(1X1) strain gauge with a resistance value of 120.3 $\pm 0.1 \Omega$. The tested data were transmitted with the CT6005 dynamic strain adaptor and the CT6005 DAQ card. Figure 6 
illustrates the layout of the strain gauge and the new magnetic coupler was approximately $22.1 \mathrm{~m} / \mathrm{s}^{2}$, which acceleration testing point for the chain. Figure 7 depicts the decreased by $14.7 \%$. In any way, the acceleration curve of layout of the 'three-machine' equipment on the working the scraper chain driven by the conventional hydraulic face.

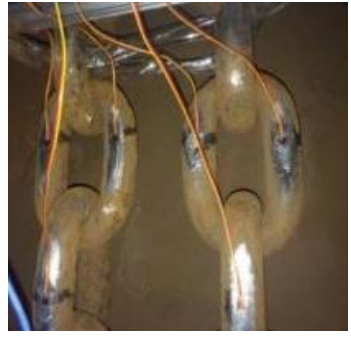

(a)

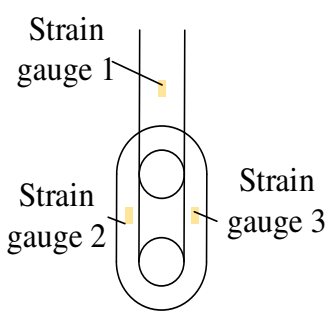

(b)

Fig.6 Layout of acceleration test points and strain gauges;(a) The physical drawing of scraper chain test; (b) Position drawing of strain gage hydraulic support

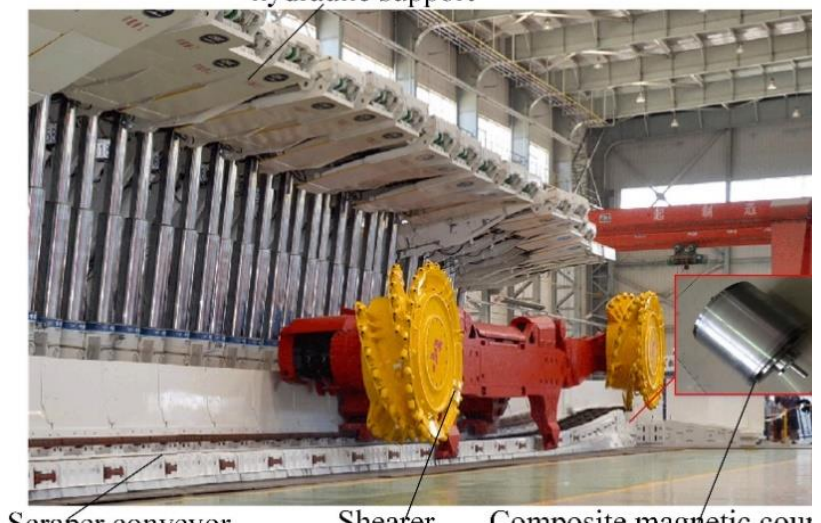

Scraper conveyor

Shearer

Composite magnetic coul

Fig. 7 Structural drawing of fully mechanized working face

During the experiment, the input revolving speed of the motor was set to $100 \mathrm{r} / \mathrm{min}$. The output shaft of the prototype was connected with one end of the chain wheel, while the input shaft was connected with the motor. Under the no-load condition, the motor was started to transfer the power of the prototype to the scraper conveyor. With the pre-startup technology, the scraper conveyor initially ran with a low speed for $5 \mathrm{~s}$ before the acceleration stage and then accelerated for $10 \mathrm{~s}$ during the acceleration stage to dynamically monitor the scraper chain acceleration. Figure 8 shows a comparison of the accelerations of the scraper chain driven by the conventional hydraulic coupler and the new magnetic coupler.

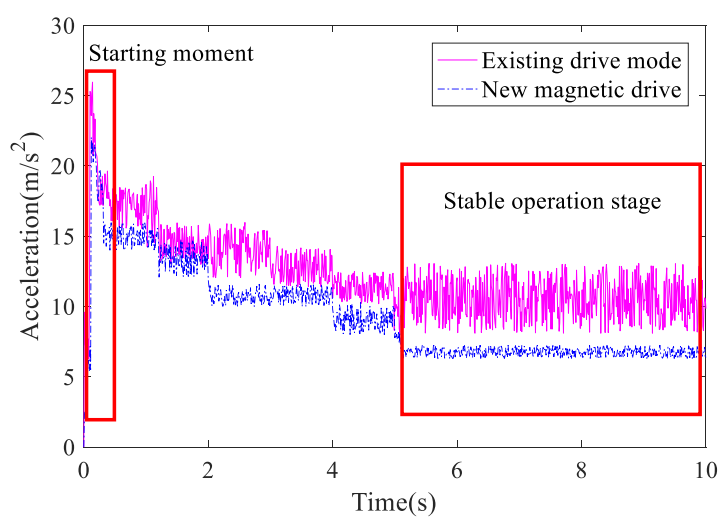

Fig. 8 Acceleration comparison diagram

The peak acceleration of the scraper chain driven by the conventional hydraulic coupler was high at approximately $25.3 \mathrm{~m} / \mathrm{s}^{2}$, whereas that of the scraper chain driven by the

coupler or the new magnetic coupler was similar during the main acceleration period and showed a fluctuated decrease trend. However, the acceleration of the scraper chain driven by the new magnetic coupler slightly varied and was smaller than that of the scraper chain driven by the hydraulic coupler. This result demonstrates that the new magnetic coupler can reduce the impact to the scraper chain during the startup and acceleration stages and protect the scraper chain.

The chain wheel driven by the new magnetic coupler was set with an input revolving speed range of $0-200 \mathrm{r} / \mathrm{min}$ to simulate the practical running condition of the scraper conveyor. The theoretical values obtained from formulae (14) and (15) were compared with the experimental values (Table 1).

Table 1 Comparative Analysis

\begin{tabular}{cccc}
\hline \multirow{2}{*}{$\begin{array}{c}\text { Input } \\
\text { speed } \\
\text { r/min })\end{array}$} & \multicolumn{4}{c}{$\begin{array}{c}\text { Acceleration of scraper chain in } \\
\text { stable transportation }\left(\mathrm{m} / \mathrm{s}^{2}\right) \\
\text { Theoretical } \\
\text { value }\end{array}$} & $\begin{array}{c}\text { Experimental } \\
\text { value }\end{array}$ & Error \\
\hline 0 & 0 & 0 & - \\
20 & 0.3 & 0.28 & 0.067 \\
40 & 1.96 & 1.79 & 0.087 \\
60 & 4.46 & 4.22 & 0.054 \\
80 & 5.93 & 5.62 & 0.052 \\
100 & 7.44 & 7.13 & 0.042 \\
120 & 17.82 & 17.01 & 0.046 \\
140 & 24.14 & 23.12 & 0.042 \\
160 & 31.54 & 29.67 & 0.059 \\
180 & 40.1 & 38.69 & 0.035 \\
200 & 49.41 & 47.01 & 0.049 \\
\hline
\end{tabular}

The comparison between the experimental and theoretical values of the scraper chain acceleration with the same input revolving speed showed that the maximum error was only $8.7 \%$, indicating an optimal fitting. Therefore, the bilateral fluctuation model of the scraper chain based on the new permanent magnetic eddy current drive system accommodated the practical motion rules and can be used to represent the fluctuation rules of the scraper chain under the effect of the new permanent magnetic eddy current drive system.

\section{CONCLUSIONS}

(1)This study introduced a new permanent magnetic eddy current drive system of the scraper conveyor and created a mathematical model for the drive system to theoretically analyse and verify its drive characteristics with an experiment. The comparison between multiple theoretical and real values of the motion acceleration of the scraper chain under the input revolving speed showed a maximum error of only $8.7 \%$, which basically verified the correctness of the proposed model.

(2)When the scraper conveyor based on the new permanent magnetic eddy current drive system was started with the pre-startup technology, its acceleration varied within a small range with a peak value of approximately $22.1 \mathrm{~m} / \mathrm{s}^{2}$, which is $14.7 \%$ lower than that of the scraper conveyor with 
a hydraulic coupler under equivalent conditions. This indicates that the new magnetic coupler can reduce the stress in the scraper conveyor, protect the scraper conveyor and improve its service life during the startup and acceleration stages. This study is useful for reducing the startup impact caused by the serious abrasion and frequent overload of the scraper chain working under bad conditions.

Acknowledgements This research was funded by National Natural Science Fund Project (Grant No. 51974004, 51874004), Nature Science Research Project of Anhui Province(Grant No. 1908085QE227), China Postdoctoral Science Foundation(Grant No. 2019M662133).We would like to thank all those who helped with the sampling.

\section{References}

M. V. Kurlenya. Influence of the Bachatsky(2019) Earthquake on Methane Emission in Roadways in Coal Mines. Journal of Mining Science, vol. 55, no. 5, pp.695-700.

Pan X , Wang K, Jiang S, et al(2020) Experimental study on ventilation supply-demand matching to dispense the stope gas disaster risk of coal mines. Geomatics, Natural Hazards and Risk, vol. 11, no. 1,pp.1299-1318.

Pan Q. , Zhou R. , Su J. , et al(2019) Automatic localization of the rotor-stator rubbing fault based on acoustic emission method and higher-order statistic. Journal of Mechanical Science and Technology, vol. 33, no. 2,pp.513-524.

Jiang S , Lv R, Wan L., et al(2020) Dynamic Characteristics of the Chain Drive System of Scraper Conveyor Based on the Speed Difference. IEEE Access, vol. 8,pp.168650168658.

Ball A. S., Kessel J. C. V.(2019)The master quorum-sensing regulators LuxR/HapR directly interact with the alpha subunit of RNA polymerase to drive transcription activation in Vibrio harveyi and Vibrio cholera. Molecular Microbiology, vol. 111, no. 5,pp.1317-1334.

Cenacewicz K., Katunin A . (2016) Modeling and simulation of longwall scraper conveyor considering operational faults.Studia Geotechnica et Mechanica, vol. 38, no. 2,pp.15-27.

Ordin, A. A, Metel'kov, A. A. (2015) Analysis of longwall face output in screw-type cutter-loader-

Bangert M, Vogel B, Junkermann W, Brachert L, Schaber K (2013) The impact of flue gas cleaning technologies in coal-fired power plants on the $\mathrm{CCN}$ distribution and cloud properties in Germany. In: AIP Conference Proceedings 1527: and-scraper conveyor system in underground mining of flat-lying coal beds.Journal of Mining Science, vol. 51, no. 6,pp.1173-1179.

Xie C., Liu Z., Mao J., et al (2018) Analysis on torsional vibration characteristics of scraper conveyor under chain clamping condition. Journal of China Coal Society, vol. 43, no. 8,pp.23482354.

Lu E., Li W., Yang X., et al(2020) Composite Sliding Mode Control of a Permanent Magnet DirectDriven System for a Mining Scraper Conveyor. IEEE Access, vol. 5, pp.22399-22408.

J. Xie, Z. Yang, X. Wang, et al(2018) Cooperative solving method of chute postures in the bending section of a scraper conveyor.Advances in Mechanical Engineering, vol.10, no. 3,pp.1-13.

D. Zhang, J. Mao, Z. Liu, et al(2016) Simulation and experimental study on dynamic characteristics of start and brake of scraper conveyor. Journal of China Coal Society, vol. 2,pp.513-521.

H. Wang, Q. Zhang, F. Xie(2017) Dynamic tension test and intelligent coordinated control system of a heavy scraper conveyor.IET Science Measurement \& Technology, vol.11, no.7,pp.871-877.

Z. Shi, Z. Zhu(2020) Case study: Wear analysis of the middle plate of a heavy-load scraper conveyor chute under a range of operating conditions.Wear, vol.380,pp.36-41

S. Hao, S. Wang, R. Malekian, et al(2017) A Geometry Surveying Model and Instrument of a Scraper Conveyor in Unmanned Longwall Mining Faces. IEEE Access, vol.5,pp.4095-4103.

W. GUO, H. WANG, G. DONG , et al(2017)A Case Study of Effective Support Working Resistance and Roof Support Technology in Thick Seam Fully-Mechanized Face Mining with Hard Roof Conditions. Sustainability, vol. 9, no. 6,pp.1-17.

D. YAN, R. LIU, M. HU, et al(2003) A New Method to Deal with The Motion Problem In Electromagnetic Field Finite Element Analysis. Proceedings of the CSEE, vol.23, no.8, pp.163-167.

S. WANG, Y. GUO, D. Li, et al(2019) Modelling and experimental research on the equivalent magnetic circuit network of hybrid magnetic couplers considering the magnetic leakage effect. Iet Electric Power Applications, vol.13, no.9, pp.1-10.

778-781 


Figures

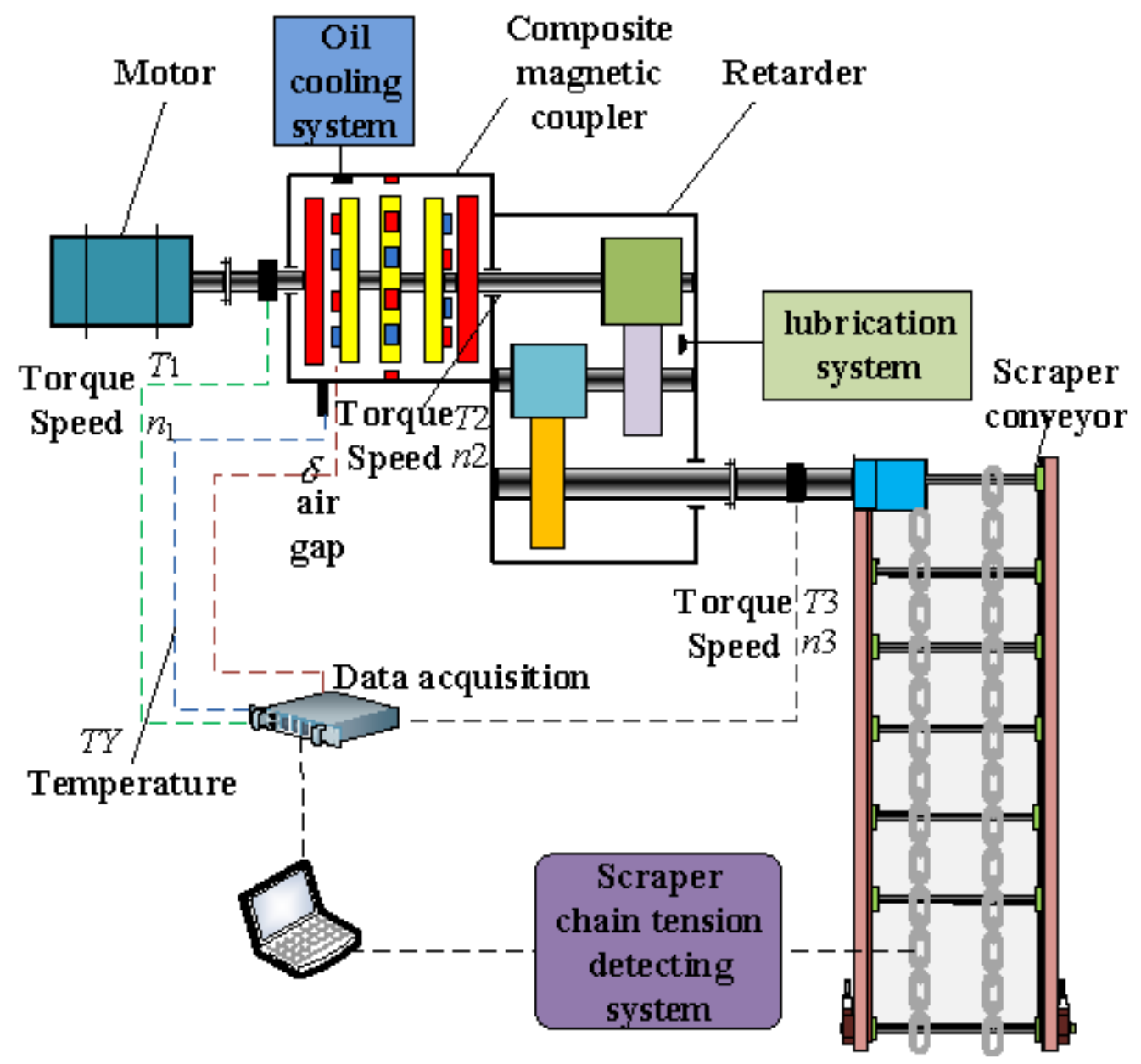

Figure 1

Schematic diagram of new permanent magnet eddy current drive system for scraper conveyor 


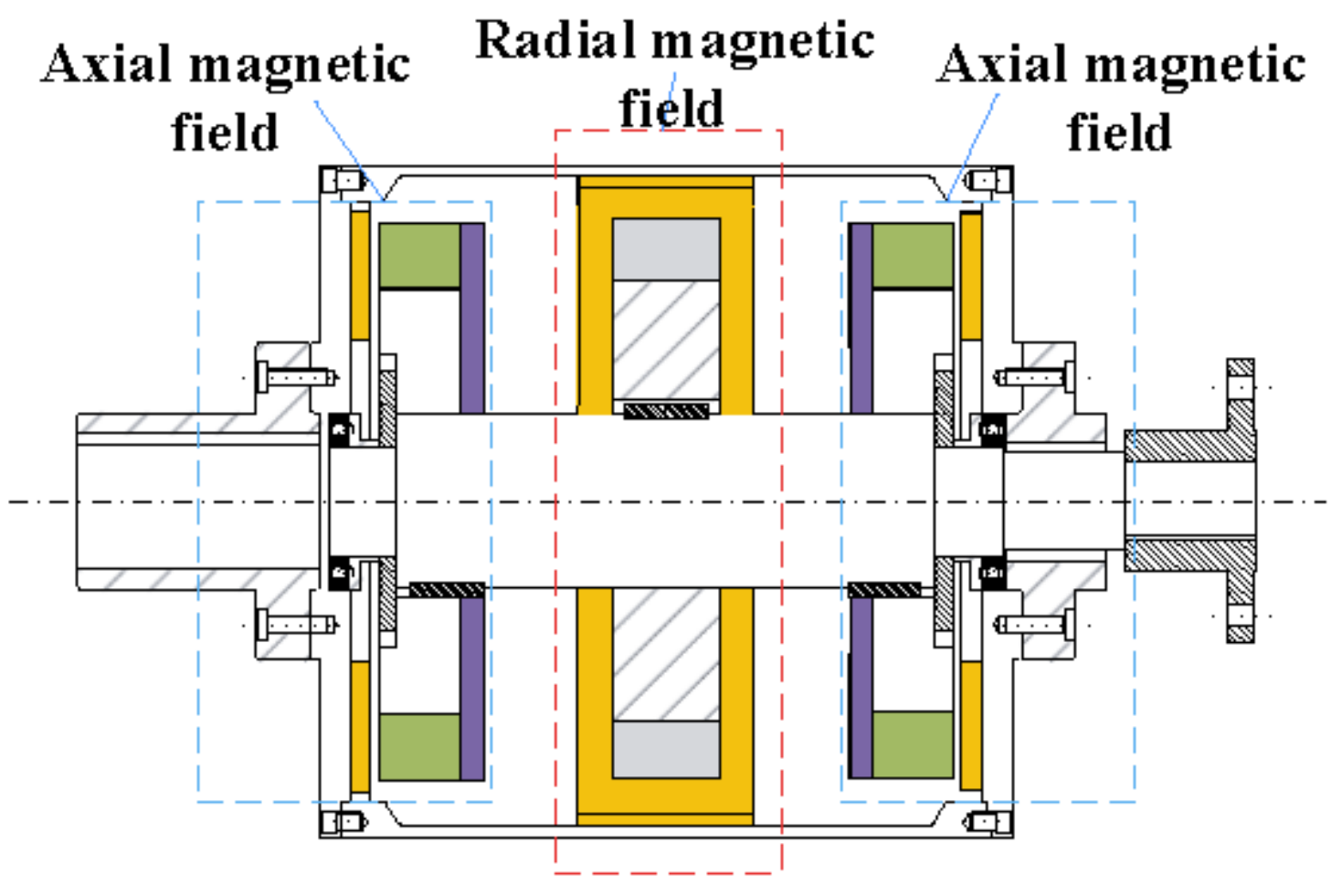

Figure 2

Schematic diagram of axial and radial magnetic fields 

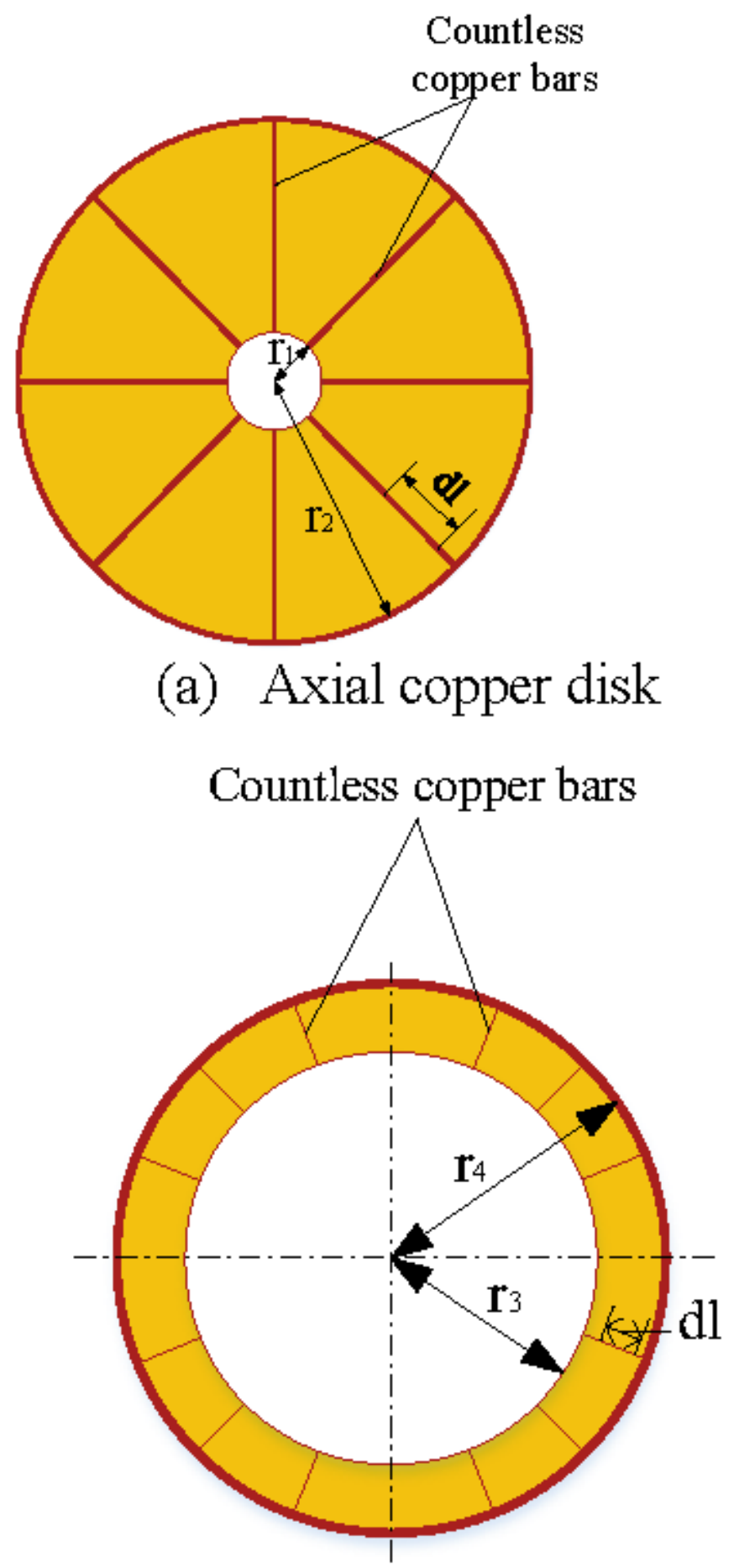

(b) Radial copper ring

Figure 3

Equivalent structure diagram 


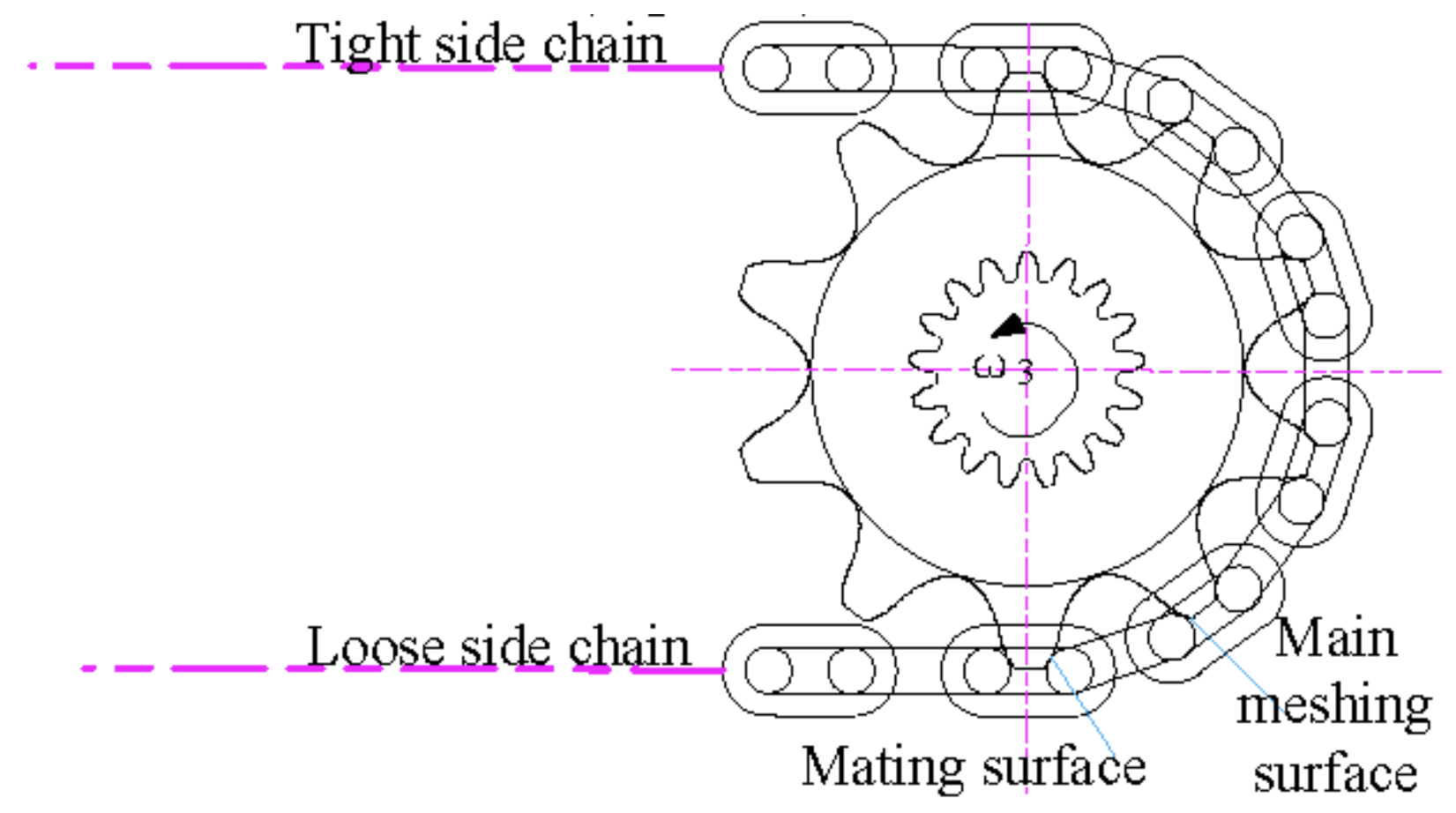

Figure 4

Stress diagram of sprocket 


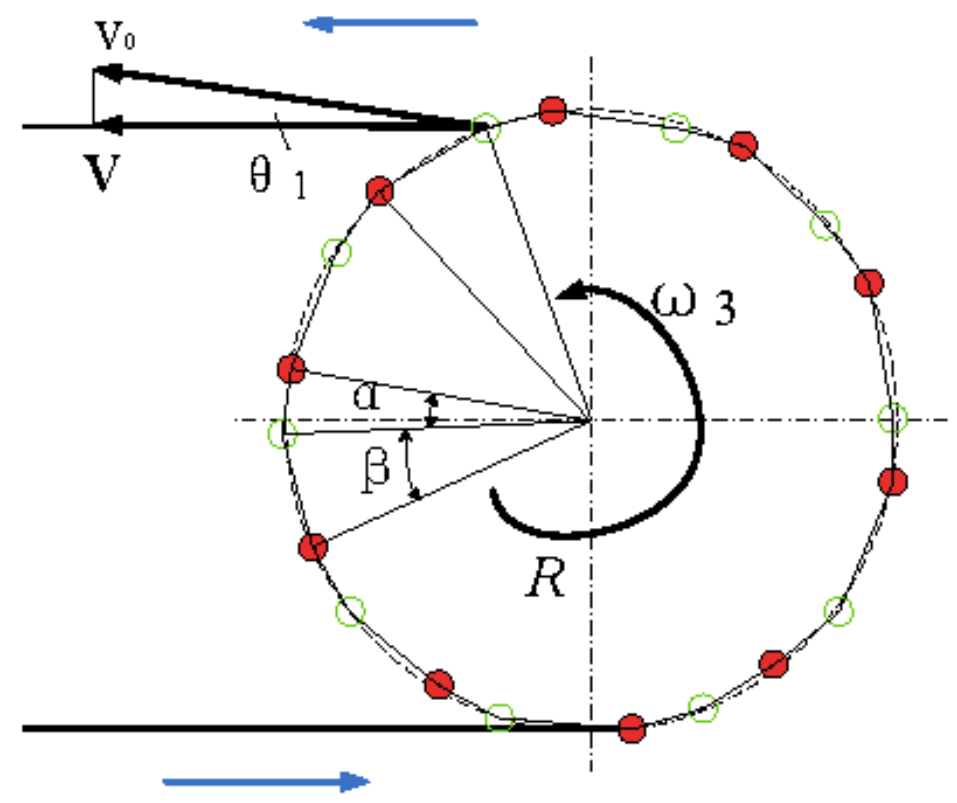

Loose side chain

(a)

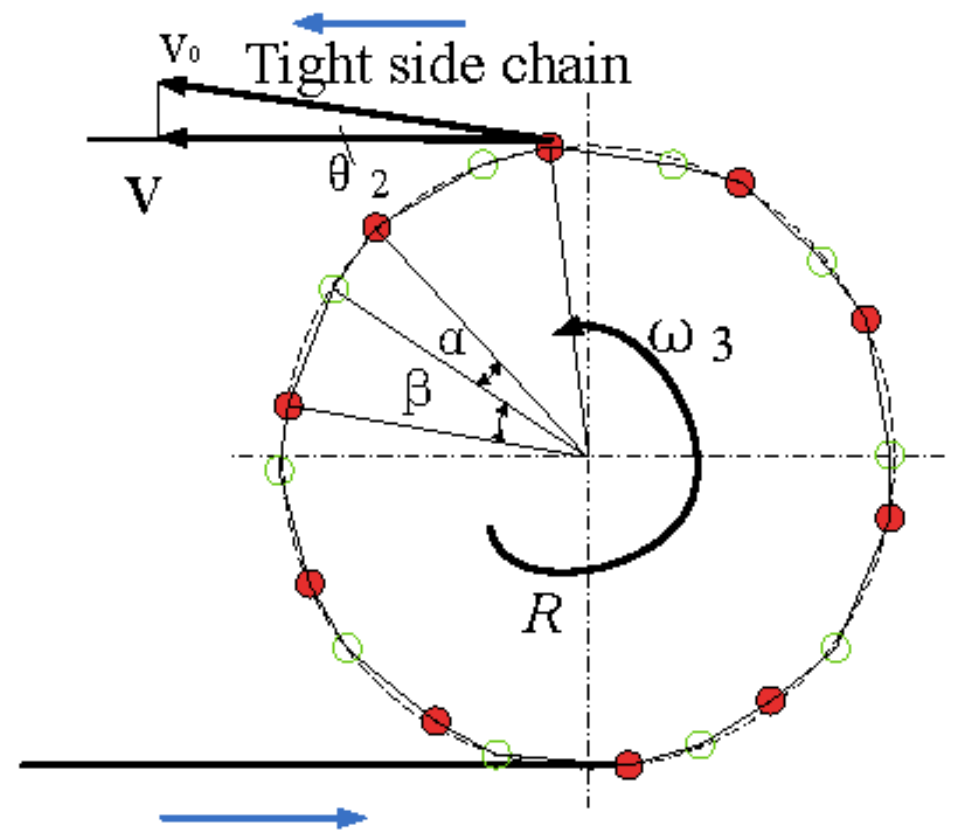

Loose side chain

(b)

Figure 5

Bilateral contact model;(a) Left-hand contact model; (b) Right-hand contact model 


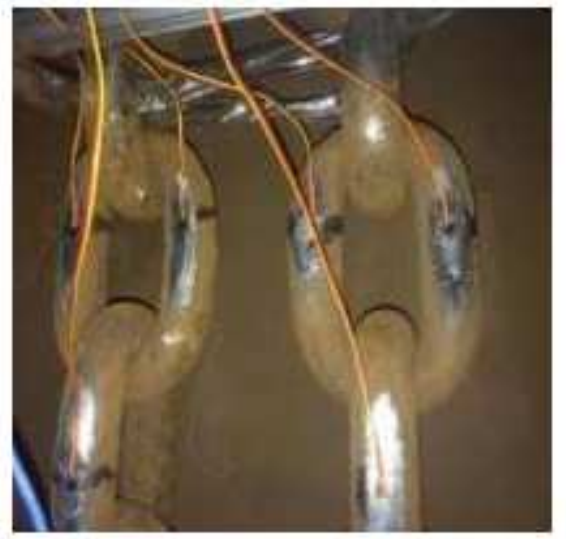

(a)

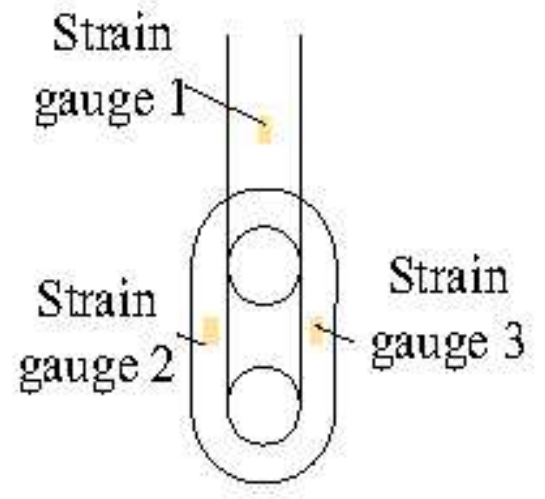

(b)

\section{Figure 6}

Layout of acceleration test points and strain gauges;(a) The physical drawing of scraper chain test; (b) Position drawing of strain gage

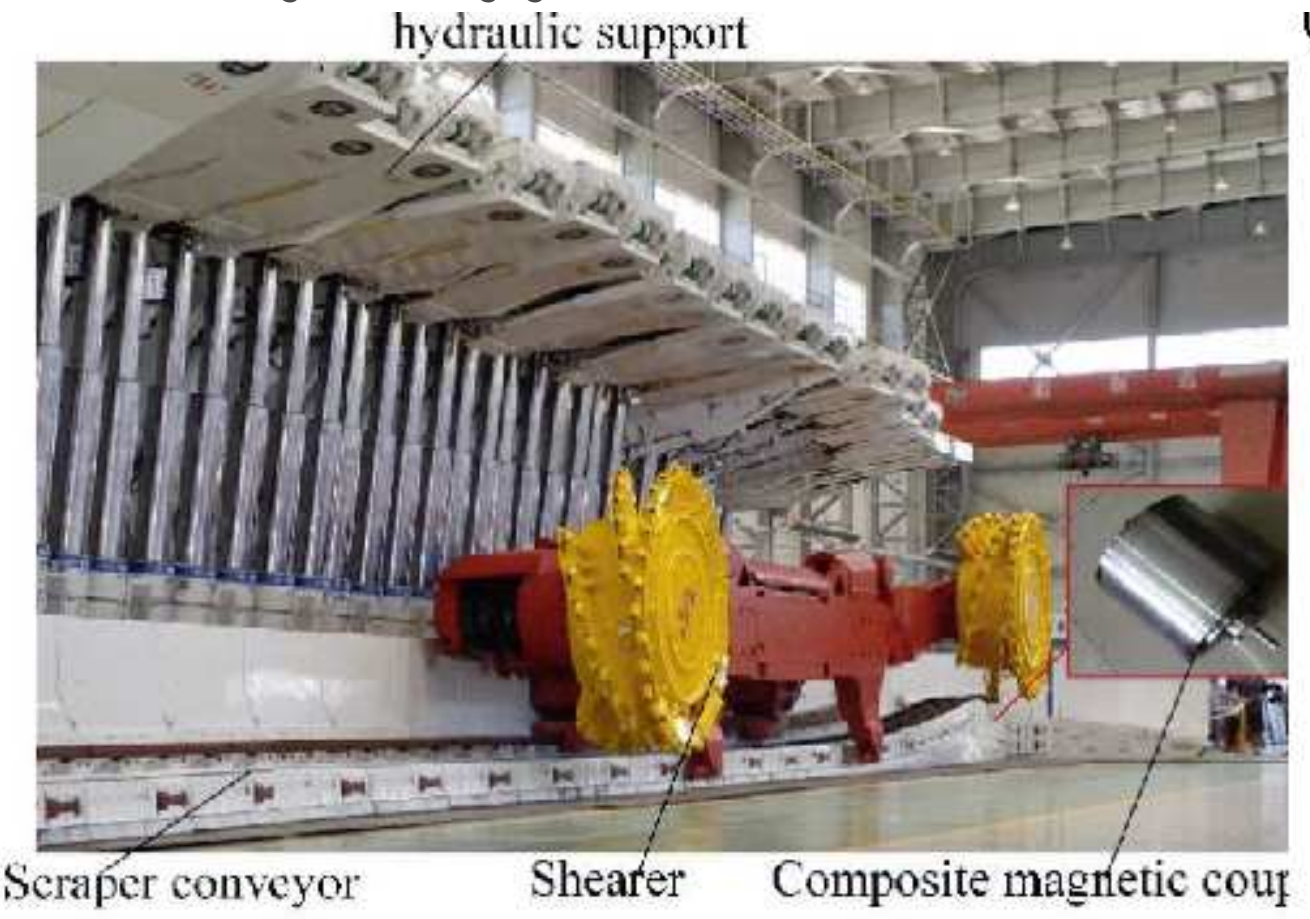

Figure 7

Structural drawing of fully mechanized working face 


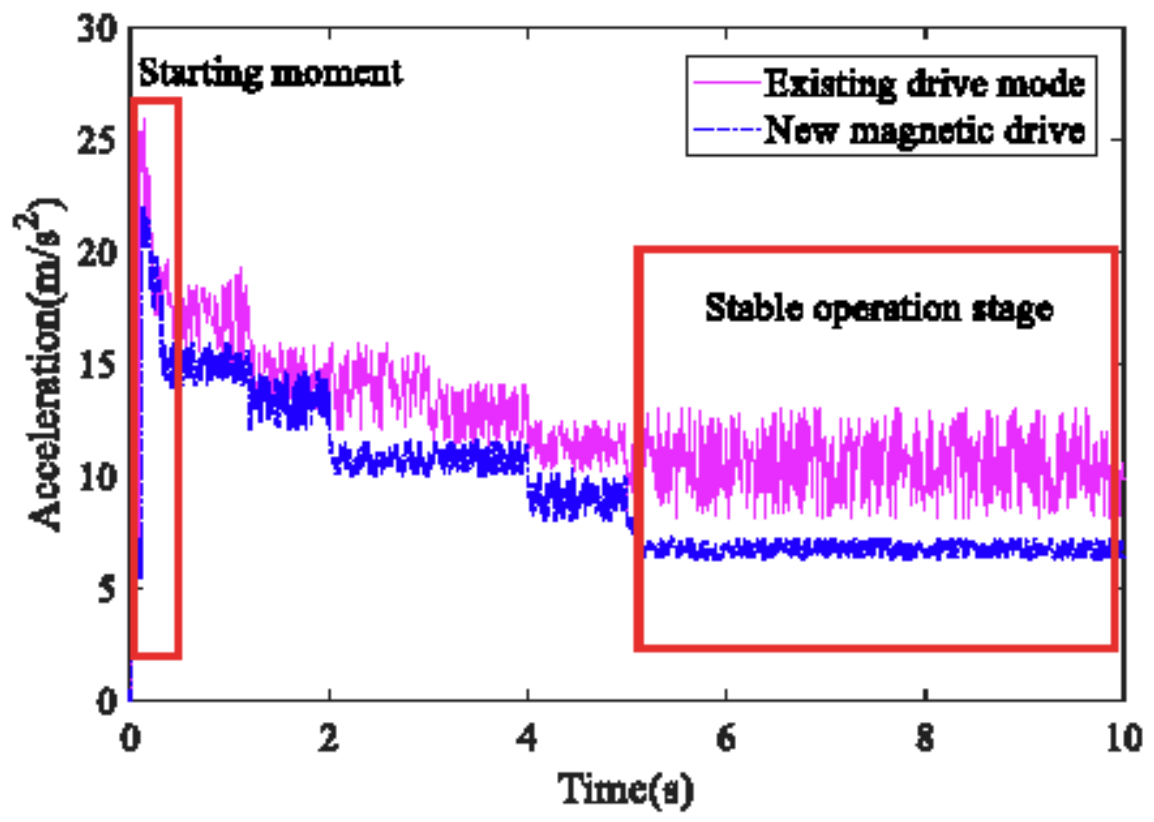

Figure 8

Acceleration comparison diagram 